\title{
THE RELATIONS BETWEEN TRAUMA EXPOSURE, SUBJECTIVE TRAUMA APPRAISALS, AND POSTTRAUMATIC STRESS SYMPTOMS IN A SAMPLE OF ROAD TRAFFIC ACCIDENT VICTIMS
}

\author{
Cornelia Măirean ${ }^{1}, \&$ Diana Mihaela Cimpoeșu ${ }^{2}$ \\ ${ }^{1}$ Department of Psychology, University Alexandru Ioan Cuza University of Iași (Romania) \\ ${ }^{2}$ University of Medicine and Pharmacy Gr.T. Popa Iasi (Romania)
}

\begin{abstract}
The aim of this present study is to assess the relations between objective trauma exposure characteristics (i.e. the number of days of hospitalization, the number of deaths), subjective trauma appraisal and posttraumatic stress symptoms in victims of road traffic accidents (RTA). We also wanted to identify the moderating role of subjective trauma appraisals in the relations between objective trauma exposure and PTSD symptoms. The study involved a sample consisting of 162 participants that experienced an RTA in the last two years $(62.3 \%$ were men). The results showed that the number of days of hospitalization, traumatic fear, and the three types of posttraumatic cognitions were positively correlated with PTSD symptoms. However, only the number of days of hospitalization, traumatic fear, and negative cognitions about the self predicted PTSD symptoms. Further, the results showed that self-blame cognitions moderated the relation between the number of deaths and PTSD symptoms. The results are in line with cognitive models of PTSD and some previous studies sustaining the fact that subjective trauma appraisals are strongly related to PTSD, compared to objective indicators of trauma exposure. The implications of these results for interventions are discussed.
\end{abstract}

Keywords: Objective trauma, subjective trauma appraisal, traumatic fear, posttraumatic cognitions, posttraumatic stress symptoms.

\section{Introduction}

Posttraumatic stress disorder (PTSD) is a major and common consequence of road traffic accidents (RTAs) that involves four clusters of symptoms, represented by intrusions of the trauma, avoidance, alteration in mood and cognitions, and arousal (APA, 2013). Objective trauma characteristics (e.g., physical injury, number of days of hospitalization post RTA) and subjective appraisals of traumas (e.g., trauma-related feelings and cognitions) are related to PTSD and may impede post-trauma recovery (Martin, Cromer, DePrince, \& Freyd, 2013). In this study, we aim to investigate if the relation between objective trauma characteristics (i.e., number of days of hospitalization post RTA, the number of deaths involved by the RTA) and PTSD symptomatology is moderated by subjective trauma appraisals (i.e., fear, posttraumatic cognitions). Understanding the relations among objective trauma, subjective trauma appraisal, and PTSD symptoms may inform practitioners in designing and implementing efficient trauma related interventions.

\subsection{Objective trauma exposure and PTSD symptomatology}

Severity of injury is the most often studied objective indicator of trauma exposure that manifested positive associations with PTSD (Koren, Norman, Cohen, Berman, \& Klein, 20005). Having a fatality occur during an RTA, severity of the initial injury and persistent medical problems following the accident are among the most consistent predictors of PTSD for victims of RTAs (Chossegros et al., 2011; Kazantzis et al., 2012; Schönenberg, Jusyte, Hautzinger, \& Badke, 2011). Further, other results showed that seeking medical attention after an RTA is a predictor of developing PTSD in the following year after the RTA (Blanchard \& Hickling, 2004). On the contrary, other studies did not find a relation between objective measures of severity of injury and PTSD in samples of victims of RTA (Nickerson, Aderka, Bryant, \& Hofmann, 2013; Stallard \& Smith, 2007). Given these mixed results, our first aim is to assess the relation between two indicators of objective trauma (i.e. the number of days of hospitalization post RTA and number of deaths involved by the RTA) and PTSD symptoms. In this study, we expect to find a positive relation between indicators of trauma exposure and PTSD symptoms. 


\subsection{Subjective trauma appraisals and PTSD symptoms}

One explanation for the mixed results concerning the relations between objective trauma characteristics and PTSD consists in the fact that subjective perceptions, rather than objective trauma characteristics, are predictive for subsequent posttraumatic symptoms (Nickerson et al., 2013; Hodgson $\&$ Webster, 2011) and more influential in the long term after trauma exposure (O'Donnell, Elliott, Wolfgang, \& Creamer, 2007). This is consistent with the assumptions of the cognitive models of PTSD (Ehlers \& Clark, 2003) that also suggest that a subjective experience, rather than an objective event, contribute to the development of PTSD.

Trauma appraisals, both at the time of trauma and later in life, manifest positive associations with PTSD symptoms (DePrince, Zurbriggen, Chu, \& Smart, 2010). Traumatic fear was found to be a stronger predictor of traumatic stress symptoms, stronger than the objective indicators of trauma in different trauma populations (e.g., Rosendal, Şalcıŏlu, Andersen, \& Mortensen, 2011), including RTAs (Hodgson \& Webster, 2011). Cognitive models of PTSD also emphasize the importance of posttraumatic cognitions, defined as negative thoughts that often occur after a trauma, in eliciting PTSD symptoms. Negative cognitions about the self, the world, and self-blame regarding the traumatic event are among the most studied cognitions in relation to PTSD (Beck, Jacobs-Lentz, Jones, Olsen, \& Clapp, 2011). Thus, previous studies documented positive relations between these posttraumatic cognitions and PTSD symptomatology in different trauma victims' samples (e.g., Barton, Boals, \& Knowles, 2013), including road traffic accidents (Bennett, Beck, \& Clapp, 2009; Ehring, Ehlers, \& Glucksman, 2008; O'Donnell et al., 2007).

Without denying the potential of different trauma appraisal to predict PTSD symptoms there is, however, some evidence that did not support a significant relation between fear for life and PTSD 6 months and 1 year after the accident (Irish et al., 2008). In other studies, only negative cognitions about the self were associated with PTSD symptoms (e.g., Moser, Hajcak, Simons, \& Foa, 2007). Moreover, the relation between self-blame cognitions and PTSD is not very clear, as some studies revealed non-significant associations among these variables (Cieslak, Benight, \& Lehman, 2008; Müller et al., 2010). Further, one study identified a negative relation between self-blame and PTSD symptoms, and not positive, as expected (Startup, Makgekgenene, \& Webster, 2007).

Given these previous findings, the second aim of the present study was to assess the relations between traumatic fear, posttraumatic cognitions and PTSD symptomatology. We expected to find a positive relation between subjective appraisals and PTSD symptoms. Further, the third aim of the present study was to identify if subjective trauma appraisals moderate the relations between objective trauma exposure and PTSD symptoms. Some previous evidence also suggests that the relation between objective trauma exposure and PTSD symptoms may vary as a function of negative trauma appraisals (Hodgson $\&$ Webster, 2011). Thus, a high level of trauma exposure determines subsequent distress, predominantly when the participants also report high levels of fear (Hodgson \& Webster, 2011). However, little is known about the interaction between objective trauma and subjective appraisals in predicting PTSD symptomatology and if objective characteristics can predict symptomatology above and beyond subjective perceptions and trauma appraisals.

\section{Methods}

\subsection{Participants}

A sample of 162 participants $(62.3 \%$ men) was involved in the present study, selected from a larger sample based on the following criterion: personal involvement in at least one major road traffic accident (at least one person lost his/her life or needed medical care) in the past two years before conducting the study. The participants' mean age was $29.37(\mathrm{SD}=9.52)$. All the participants were drivers and had a driving experience between 1 and 29 years $(M=8.34 ; S D=7.19)$. During the accident, 73.5\% of the participants were driving the cars, while $26.5 \%$ were passengers in one of the cars involved in the accident. The protocol for the study was approved by the Ethical Board of Alexandru Ioan Cuza University of Iaşi, Romania. After signing the informed consent, the participants were asked to report their experience concerning involvement in traffic accidents and, based on their answers, a specific set of questionnaires were offered. Only the participants that reported the experience of a traffic accident in the past two years were included in this study.

\subsection{Instruments}

PTSD Checklist for DSM-5 (PCL-5) (Weathers et al., 2013) is a 20-item self-reporting scale that measures PTSD symptomatology presented in the past month. The participants rated how much they were bothered by the presence of intrusions, avoidance, alterations in mood and cognition as well as arousal. The items are rated on a 5-point Likert scale from 0 (not at all) to 4 (extremely). In the present study, the total score was computed and the Alpha Cronbach coefficient is .92.

A trauma appraisal questionnaire (DePrince, Zurbriggen, Chu, \& Smart, 2010) was used to measure the fear after the accident that also persists in the present (11 items). The participants were asked to think about the traffic accident that happened in the past two years, to read each item and to evaluate 
how much they agree or disagree with the description of the item now when they think about the event. Each item was evaluated on a five point Likert scale, from 1 (strongly disagree) to 5 (strongly agree). The Alpha Cronbach coefficient in our sample is .89.

The Posttraumatic Cognition Inventory (PTCI) (Foa, Ehlers, Clark, Tolin, \& Orsillo, 1999) is a 36-item measure, designed to assess the severity of three posttraumatic cognitions: negative cognitions about the self ( 21 items), negative cognitions about the world ( 7 items) and self-blame ( 5 items). Items are rated on a 7-point Likert scale from 1 (totally disagree) to 7 (totally agree). The Alpha Cronbach coefficients in our sample were .89 (negative self), .78 (negative world) and .77 (self-blame).

The objective trauma appraisal was measured with 2 items that require the following information: the number of days of hospitalization for the participant (if any) and the total number of deaths as a consequence of the accident.

The demographic questionnaire asked the participants to report their age, gender, education, driving experience, the number of accidents they were engaged in.

\section{Results}

\subsection{Preliminary analysis}

We conducted an independent sample $t$-test comparing the male and female participants' means on PTSD symptoms, traumatic fear and posttraumatic cognitions. The results showed that the women reported a high level of PTSD symptoms $(M=2.45, S D=0.72)$, traumatic fear $(M=2.81, S D=0.83)$ and posttraumatic cognitions related to self $(M=1.78, S D=0.58)$, compared to the men (PTSD symptoms: $M=1.93, S D=0.77$; traumatic fear: $M=2.52, S D=0.93$; posttraumatic cognitions related to self: $M=1.58, S D=0.59$ ). For posttraumatic cognitions related to the world and self-blame, there are no significant differences between the men and women (all $p>.050$ ).

\subsection{Associations among the study's variables}

In order to assess the associations among the study's variables, Pearson correlations were computed (see Table 2). The PTSD symptoms positively correlated with traumatic fear, the number of days of hospitalization, as well as with the three types of traumatic cognitions analyzed in the present study.

Table 1. Pearson correlations between all the study variables.

\begin{tabular}{|c|c|c|c|c|c|c|c|c|}
\hline & 1 & 2 & 3 & 4 & 5 & 6 & 7 & 8 \\
\hline 1. The number of days of hospitalization & 1 & & & & & & & \\
\hline 2. The number of deaths & .03 & 1 & & & & & & \\
\hline 3. PTCI negative self & $.21 *$ & .06 & & & & & & \\
\hline 4. PTCI negative world & .07 & .13 & $.46 * * *$ & & & & & \\
\hline 5. PTCI self-blame & $.19 *$ & .02 & $.45 * * *$ & $.26 * *$ & & & & \\
\hline 6. Traumatic fear & $.32 * * *$ & $.24 * *$ & $.45 * * *$ & $.29 * * *$ & $.21 * *$ & & & \\
\hline 7. PTSD symptoms & $.17 *$ & .14 & $.61 * * *$ & $.22 * *$ & $.26 * *$ & $.57 * * *$ & & \\
\hline 8. Age & .02 & .11 & .06 & .06 & .02 & .05 & .09 & \\
\hline 9. The number of months from the accident & .05 & -.11 & .06 & .003 & .02 & .15 & .08 & $.16^{*}$ \\
\hline
\end{tabular}
$* p<.05,{ }^{* *} p<0.01, * * * p<.001 ; N=162$

\subsection{The relations between objective trauma indicators, subjective trauma appraisals, and PTSD symptoms}

The results showed that from the objective indicators of trauma, the number of days of hospitalization is a significant positive predictor for PTSD symptoms $(\beta=.17, p=.020)$. The number of deaths did not represent significant predictors of PTSD symptoms $(\beta=.13, p=.070)$. Further, traumatic fear $(\beta=.37, p<.001)$ and negative cognitions about the self $(\beta=.48, p<.001)$ significantly predicted PTSD symptoms, while negative cognitions about the world $(\beta=-.08, p=.173)$ and self-blame $(\beta=.004$, $p=.950)$ are non-significant predictors of PTSD symptoms. The objective trauma indicators explained $5.2 \%$ of the variance in PTSD symptoms above and beyond the variance explained by the subjective trauma appraisals, when gender and the number of months since the RTA occurred are controlled. The subjective trauma appraisals (i.e. traumatic fear, posttraumatic cognitions) explained $40.60 \%$ of the variance in PTSD symptoms.

The number of deaths interacted with self-blame cognitions in predicting PTSD symptoms ( $\beta=-.20, p=.034)$. Self-blame cognitions dampens the positive relationship between the number of deaths after RTA and PTSD symptomatology.

\section{Discussion}

This study aims to investigate the relations between characteristics of objective trauma exposure (i.e. the number of days of hospitalization, the number of deaths), subjective trauma appraisals 
(i.e. traumatic fear, posttraumatic cognitions) and PTSD symptoms in a sample of motor vehicle accident victims, following two years after the accident.

Our results are in line with previous studies that highlighted the fact that subjective trauma appraisals manifest stronger connections with PTSD symptoms, compared to objective trauma exposure (Hodgson \& Webster, 2011; Nickerson et al., 2013). Thus, in this study, the number of days of hospitalization was significantly positively related to PTSD symptoms, and this relation was weaker compared to the relations between the negative trauma appraisals and PTSD symptoms. From the subjective trauma appraisals, traumatic fear and posttraumatic cognitions about the self are the only significant predictors of PTSD symptoms. Previous literature also sustains the important role of fear in determining posttraumatic symptomatology, given the fact that fear implies an ongoing sense of threat and helplessness (Rosendal et al., 2011). Moreover, negative cognitions about the self were constantly related to PTSD symptoms, in samples of RTA victims (Bennett et al., 2009; Ehring et al., 2008). Therefore, perceiving the self as worthless or incompetent is more detrimental for an individual's mental health than perceiving the world as a dangerous place. The non-significant relation between self-blame and PTSD were also reported in previous studies (Cieslak et al., 2008; Moser et al., 2007) and was explained through the way these negative cognitions are measured, with only 5 items that assess both characterological and behavioral self-blame (Müller et al., 2010). These two types of self-blame may represent distinct factors that may manifest different relations with posttraumatic symptomatology (Mueller \& Major, 1989). Thus, although the relation between posttraumatic cognitions and PTSD symptoms was often addressed in previous studies, more research is needed in order to clarify how and under what circumstance these cognitions are related to posttraumatic symptoms.

Further, our results showed that the relations between objective indicators of trauma exposure and PTSD symptoms are moderated by self-blame cognitions. Specifically, in the cases of accidents with higher number of deaths, higher PTSD symptomatology was reported by the participants with low level of self-blame. On the contrary, when the accidents involved lower number of deaths, higher PTSD symptomatology was reported by the participants with high level of self-blame. These results may be explained by the fact that high self-blame is particularly detrimental in the cases of less severe traumas. When the accident caused more deaths, high self-blame may be generated by the fact of being responsible for the accidents. This high level of self-blame prevents the development of other posttraumatic symptoms. Overall, these results highlight the complex relations that may exist between trauma exposure and posttraumatic symptomatology and also suggest that trauma exposure alone is not associated with posttraumatic stress symptoms, when it is not also associated with negative subjective trauma appraisals.

When interpreting these results, some limitations need to be considered. First, the cross-sectional nature of the study does not allow us to establish causal relations among the variables. Thus, future longitudinal studies are necessary in order to establish the fact that objective trauma exposure and negative trauma appraisal can be determinant factors for PTSD symptoms. Second, the small sample size and the fact that the participants are victims of RTAs limit the generalization of the results on this specific population.

In conclusion, the results of this current study provide support for the role of negative subjective trauma appraisals in the relationships between objective indicators of trauma exposure and PTSD symptoms. The number of deaths, posttraumatic cognitions about the world, and self-blame are non-significant predictors of PTSD symptoms, while the number of days of hospitalization, traumatic fear and negative cognitions about the self, represent significant positive predictors of PTSD symptoms. Additionally, self-blame cognitions interacted with number of deaths in predicting PTSD symptoms. These results are in line with the cognitive models of PTSD showing that subjective trauma perceptions are more important factors associated with posttraumatic stress symptoms after the trauma of an RTA. Given the cross-sectional nature of the current study, future research is needed to understand the causal relations among objective trauma exposure, subjective trauma appraisals, and PTSD symptoms.

\section{Acknowledgements}

This work was supported by a grant of Ministry of Research and Innovation, CNCS - UEFISCDI, project number PN-III-P1-1.1-PD-2016-0902, within PNCDI III.

\section{References}

American Psychiatric Association. (2013). Diagnostic and statistical manual of mental disorders (DSM-5®). 5th ed. Washington, DC: American Psychiatric Press.

Barton, S., Boals, A., \& Knowles, L. (2013). Thinking about trauma: The unique contributions of event centrality and posttraumatic cognitions in predicting PTSD and posttraumatic growth. Journal of Traumatic Stress, 26(6), 718-726.

Beck, J. G., Jacobs-Lentz, J., Jones, J., Olsen, S. A., \& Clapp, J. D. (2011). Understanding post-trauma cognitions and beliefs. In L. Zoellner, \& N. C. Feeny (Eds.), Facilitating resilience and recovery following traumatic events (pp. 167-190). Guilford Publications. 
Bennett, S. A., Beck, J. G., \& Clapp, J. D. (2009). Understanding the relationship between posttraumatic stress disorder and trauma cognitions: The impact of thought control strategies. Behaviour Research and Therapy, 47(12), 1018-1023.

Blanchard, E. B., \& Hickling, E. J. (2004). After the crash: Psychological assessment and treatment of survivors of motor vehicle accidents. American Psychological Association.

Chossegros, L., Hours, M., Charnay, P., Bernard, M., Fort, E., Boisson, D., ... \& Laumon, B. (2011). Predictive factors of chronic post-traumatic stress disorder 6 months after a road traffic accident. Accident Analysis \& Prevention, 43(1), 471-477.

Cieslak, R., Benight, C. C., \& Lehman, V. C. (2008). Coping self-efficacy mediates the effects of negative cognitions on posttraumatic distress. Behaviour Research and Therapy, 46(7), 788-798.

DePrince, A. P., Zurbriggen, E. L., Chu, A. T., \& Smart, L. (2010). Development of the trauma appraisal questionnaire. Journal of Aggression, Maltreatment \& Trauma, 19(3), 275-299.

Ehlers, A., \& Clark, D. M. (2000). A cognitive model of posttraumatic stress disorder. Behaviour Research and Therapy, 38(4), 319-345.

Ehring, T., Ehlers, A., \& Glucksman, E. (2008). Do cognitive models help in predicting the severity of posttraumatic stress disorder, phobia, and depression after motor vehicle accidents? A prospective longitudinal study. Journal of Consulting and Clinical Psychology, 76(2), 219-230.

Foa, E. B., Ehlers, A., Clark, D. M., Tolin, D. F., \& Orsillo, S. M. (1999). The posttraumatic cognitions inventory (PTCI): Development and validation. Psychological Assessment, 11(3), 303-314.

Hodgson, R. C., \& Webster, R. A. (2011). Mediating role of peritraumatic dissociation and depression on post-MVA distress: path analysis. Depression and Anxiety, 28(3), 218-226.

Irish, L., Ostrowski, S. A., Fallon, W., Spoonster, E., Dulmen, M. V., Sledjeski, E. M., \& Delahanty, D. L. (2008). Trauma history characteristics and subsequent PTSD symptoms in motor vehicle accident victims. Journal of Traumatic Stress: Official Publication of the International Society for Traumatic Stress Studies, 21(4), 377-384.

Kazantzis, N., Kennedy-Moffat, J., Flett, R. A., Petrik, A. M., Long, N. R., \& Castell, B. (2012). Predictors of chronic trauma-related symptoms in a community sample of New Zealand motor vehicle accident survivors. Culture, Medicine, and Psychiatry, 36(3), 442-464.

Koren, D., Norman, D., Cohen, A., Berman, J., \& Klein, E. M. (2005). Increased PTSD risk with combat-related injury: a matched comparison study of injured and uninjured soldiers experiencing the same combat events. American Journal of Psychiatry, 162(2), 276-28.

Martin, C. G., Cromer, L. D., DePrince, A. P., \& Freyd, J. J. (2013). The role of cumulative trauma, betrayal, and appraisals in understanding trauma symptomatology. Psychological Trauma: Theory, Research, Practice, and Policy, 5(2), 110-118.

Moser, J. S., Hajcak, G., Simons, R. F., \& Foa, E. B. (2007). Posttraumatic stress disorder symptoms in trauma-exposed college students: The role of trauma-related cognitions, gender, and negative affect. Journal of Anxiety Disorders, 21(8), 1039-1049.

Mueller, P., \& Major, B. (1989). Self-blame, self-efficacy, and adjustment to abortion. Journal of Personality and Social Psychology, 57(6), 1059-1068.

Müller, J., Wessa, M., Rabe, S., Dörfel, D., Knaevelsrud, C., Flor, H., ... \& Karl, A. (2010). Psychometric properties of the Posttraumatic Cognitions Inventory (PTCI) in a German sample of individuals with a history of trauma. Psychological Trauma: Theory, Research, Practice, and Policy, 2(2), 116-125.

Nickerson, A., Aderka, I. M., Bryant, R. A., \& Hofmann, S. G. (2013). The role of attribution of trauma responsibility in posttraumatic stress disorder following motor vehicle accidents. Depression and Anxiety, 30(5), 483-488.

O'Donnell, M. L., Elliott, P., Wolfgang, B. J., \& Creamer, M. (2007). Posttraumatic appraisals in the development and persistence of posttraumatic stress symptoms. Journal of Traumatic Stress, 20(2), 173-182.

Rosendal, S., Şalcığlu, E., Andersen, H. S., \& Mortensen, E. L. (2011). Exposure characteristics and peri-trauma emotional reactions during the 2004 tsunami in Southeast Asia-what predicts posttraumatic stress and depressive symptoms?. Comprehensive Psychiatry, 52(6), 630-637.

Schönenberg, M., Jusyte, A., Hautzinger, M., \& Badke, A. (2011). Early predictors of posttraumatic stress in accident victims. Psychiatry Research, 190(1), 152-155.

Stallard, P., \& Smith, E. (2007). Appraisals and cognitive coping styles associated with chronic post-traumatic symptoms in child road traffic accident survivors. Journal of Child Psychology and Psychiatry, 48(2), 194-201.

Weathers, F. W., Litz, B. T., Keane, T. M., Palmieri, P. A., Marx, B. P., \& Schnurr, P. P. (2013). The ptsd checklist for dsm-5 (pcl-5). Scale available from the National Center for PTSD at www. ptsd. va. gov. 